\title{
Consumo, Digestibilidade Aparente Total, Produção e Composição do Leite em Vacas no Terço Médio da Lactação Alimentadas com Níveis Crescentes de Proteína Bruta no Concentrado ${ }^{1}$
}

\section{Mara Lúcia Albuquerque Pereira ${ }^{2}$, Sebastião de Campos Valadares Filho ${ }^{3}$, Rilene Ferreira Diniz Valadares $^{4}$, José Maurício de Souza Campos ${ }^{3}$, Maria Ignez Leão ${ }^{3}$, César Augusto Ramos Pereira², Polyana Albino Silva ${ }^{5}$, Sandro de Souza Mendonça ${ }^{2}$}

\begin{abstract}
RESUMO - Avaliaram-se os consumos, as digestibilidades aparentes dos nutrientes e a produção e composição do leite de vacas no terço médio da lactação recebendo dietas contendo níveis crescentes de proteína bruta (PB) no concentrado (20;23;26 e 29\% da matéria natural - MN). Foram utilizadas 12 vacas em lactação da raça Holandesa, puras e mestiças, distribuídas em três quadrados latinos (4x4). Foram utilizados quatro períodos de 15 dias cada, sendo uma semana considerada de adaptação. A dieta consistiu de $70 \%$ de silagem de milho como volumoso e 30\% de concentrado. Os consumos e as digestibilidades da matéria seca (MS), matéria orgânica (MO), extrato etéreo (EE), carboidratos totais (CHOT), fibra em detergente neutro (FDN) e carboidratos não-fibrosos (CNF) e o consumo de nutrientes digestíveis totais (NDT) não foram alterados, enquanto o consumo e a digestibilidade de PB aumentaram em função dos níveis de PB no concentrado. A produção de leite (PL) corrigida para 3,5\% de gordura, as quantidades de gordura e proteína no leite aumentaram linearmente com o aumento dos níveis de PB no concentrado. No entanto, a PL de 19,21 kg/dia e a PL corrigida para 3,5\% de gordura de $20,74 \mathrm{~kg} /$ dia para o nível de $23 \%$ de PB na MN do concentrado, foram muito próximas daquelas obtidas nos níveis de 26 e $29 \%$ de PB no concentrado. O concentrado contendo $23 \%$ de PB na MN utilizado na proporção de 30\%, que correspondeu a 12,3\% de PB na MS da dieta total, proporcionou melhor eficiência na produção de leite em vacas produzindo em média $20 \mathrm{~kg} / \mathrm{dia}$ de leite no terço médio da lactação e alimentadas com silagem de milho na proporção de $70 \%$ na MS da dieta total.
\end{abstract}

Palavras-chave: composição química, degradabilidade ruminal, eficiência de utilização de compostos nitrogenados, farelo de soja, proteína na dieta, silagem de milho

\section{Intake, Total Apparent Digestibility, Milk Production and Composition in Mid Lactation Cows Fed with Increasing Levels of Crude Protein in the Concentrate}

ABSTRACT - Intake, total apparent digestibility of nutrients and milk production and composition were evaluated in mid lactation cows fed with increasing levels of crude protein (CP) in the concentrate (20, 23, 26 and 29\% natural matter-NM). Twelve Holstein crossbred lactating cows were assigned to three latin square (4x4), in four periods of 15 days each (one week of adaptation). The feeding consisted of $70 \%$ of corn silage and $30 \%$ of concentrate. Intakes and digestibilities of dry matter (DM), organic matter $(\mathrm{OM})$, ether extract (EE), total carbohydrates (TCHO), neutral detergent fiber (NDF) and non-fiber carbohydrates (NFC) and total digestible nutrients (TDN) were not altered, while CP intake and digestibility increased in response to CP levels in the concentrate. Corrected milk production (MP) for $3.5 \%$ fat, fat and protein concentrations in milk increased linearly with an increasing of CP levels in the concentrate. Nonetheless, for CP levels of $23 \%$ in the natural matter of the concentrate, $\mathrm{MP}$ of $19.21 \mathrm{~kg} / \mathrm{day}$ and corrected MP for $3.5 \%$ fat of $20.74 \mathrm{~kg} /$ day were very close to the values obtained for 26 and $29 \%$ CP levels in the concentrate. The $23 \%$ CP level in the natural matter of the concentrate, in a proportion of $30 \%$, correspondent to $12.3 \%$ of CP in DM, showed better results of milk production. Average milk production for mid lactation cows fed with corn silage was of $20 \mathrm{~kg} / \mathrm{day}$.

Key Words: chemical composition, corn silage, efficiency of nitrogen compounds assimilation, protein in the diet, ruminal degradability, soybean meal

\section{Introdução}

Quando as vacas iniciam o terço médio de lactação já ultrapassaram o pico de produção de leite (de 4 a 6 semanas após o parto) e, uma vez que o pico de ingestão de matéria seca (MS) é alcançado, em torno de 90 dias, geralmente não ocorre mais a perda de peso corporal (Neiva, 1998). Portanto, o ideal é fornecer uma ração que promova melhoria na persistência da lactação.

\footnotetext{
1 Parte da tese de Doutorado em Zootecnia apresentada pelo primeiro autor à UFV.

2 Professor(a) do curso de Zootecnia - UESB - Pç. Primavera, 40 - Itapetinga, BA - 45700-000. E.mail: mara@uesb.br; carp@uesb.br; sandromendonca@yahoo.com.br

3 Professor(a) do Departamento de Zootecnia - UFV - Viçosa, MG. E.mail: scvfilho@ufv.br; jmcampos@ufv.br; mileao@ufv.br

${ }^{4}$ Professora do Departamento de Medicina Veterinária - UFV - Viçosa, MG. E.mail: rilene@ufv.br

${ }^{5}$ Mestranda em Zootecnia - UFV - Viçosa, MG.
} 
De acordo com Robinson et al. (1991), quando as taxas de ingestão de MS são altas, vacas lactantes podem consumir dietas com menores concentrações de proteína bruta $(\mathrm{PB})$ e ainda assim manter os requerimentos para proteína metabolizável, tornandose desnecessário o fornecimento de proteína nãodegradável no rúmen (PNDR) na dieta. Além disso, quando há maior ingestão de MS, a taxa de passagem pode aumentar, resultando aumento do suprimento de PNDR em razão do menor tempo disponível para degradação no rúmen.

Reduzir a concentração de PB dietética para vacas em lactação é o modo mais comum e prático para diminuir as perdas de compostos nitrogenados e os custos de produção em experimentos de alimentação (Smits et al., 1995; Dinn et al., 1998; Paul et al., 1998). Se a redução da concentração de PB na dieta for significativamente abaixo das recomendações, é certa a queda na produção de leite (Dinn et al., 1998; Kalsheur et al., 1999).

Antes de se alterar os teores de PB na dieta, é importante determinar as concentrações ótimas de proteína degradável no rúmen (PDR) e PNDR em relação ao consumo de proteína total, pois quantidades adequadas de PDR são necessárias para ótima eficiência de síntese microbiana e obtenção de produtividade animal adequada, com quantidade mínima de proteína dietética (NRC, 2001).

A proteína microbiana perfaz 60 a $75 \%$ da proteína absorvida pelo animal, sendo o restante de origem dietética (PNDR) e também de origem endógena. A maximização da produção de proteína microbiana parte de uma estratégia da dieta bem equilibrada na relação energia:proteína, sendo constituída por concentrado e volumosos de boa qualidade.

Substituindo parcialmente farelo de soja por glúten de milho e farinha de sangue, McCormick et al. (1999) conseguiram aumentos significativos na produção de leite em vacas no terço inicial da lactação. Estes autores observaram que uma variação de $5,8 \%$ de PNDR e $17,3 \%$ de PDR ou $5,0 \%$ de PNDR e $12,7 \%$ de PDR para 6,8\% de PNDR e $11 \%$ de PDR aumentou substancialmente a produção de leite de 35 para 41 $\mathrm{kg}$ de leite por dia, no início da lactação, mas não encontraram diferença no terço médio da mesma.

Similarmente, Kalscheur et al. (1999) fizeram um estudo da lactação total utilizando diferentes níveis de PNDR e PDR e encontraram que níveis de 7,1\% de PNDR e $10,3 \%$ de PDR na MS da dieta, no início da lactação, resultaram em aumentos significativos da produção e da proteína do leite. Níveis de 5-6\% de PNDR e $8-9 \%$ de PDR na MS dietética suportaram produções similares de 20 a $27 \mathrm{~kg}$ de leite, quando as vacas se encontravam nos terços médio e final da lactação.

Baseando-se na literatura, é evidente que o nível de PNDR é crítico durante o terço inicial da lactação para vacas de alta produção e também é evidente que PNDR é de menor importância durante as fases média ou final da lactação, podendo ser reduzido para 2-4\% (Gustafsson et al., 2003). Por outro lado, a PDR deve suprir as necessidades para síntese microbiana e a maioria dos dados indica que um nível de PDR entre 10 e $12 \%$ da MS dietética é o nível ótimo para produção de leite ao longo da lactação. Isso corresponderia a $17-18 \%$ de PB na base da MS da dieta no terço inicial da lactação e 13-14\% de PB nos terços médio e final.

A maioria dos estudos recentes tem utilizado vacas de alta produção e dietas suplementadas com proteína de baixa degradabilidade. Além disso, são estudadas vacas somente na primeira fase da lactação. Portanto, informações são necessárias para vacas de média produção no terço médio de lactação.

$\mathrm{O}$ experimento foi realizado com os objetivos de avaliar o efeito dos níveis de PB no concentrado sobre a produção e composição do leite, os consumos e as digestibilidades aparentes totais de matéria seca (MS), matéria orgânica $(\mathrm{MO})$, proteína bruta $(\mathrm{PB})$, extrato etéreo (EE), carboidratos totais (CHOT), fibra em detergente neutro (FDN) e carboidratos não-fibrosos (CNF), os consumos de nutrientes digestíveis totais (NDT), bem como estimar a degradabilidade in situ dos alimentos utilizados nas dietas de vacas no terço médio da lactação.

\section{Material e Métodos}

O experimento foi conduzido na Unidade de Ensino, Pesquisa e Extensão em Gado de Leite (UEPE-GL) do Departamento de Zootecnia (DZO) da Universidade Federal de Viçosa (UFV), Viçosa-MG. Foram utilizadas 12 vacas da raça Holandesa, puras e mestiças (Holandês x Zebu) em lactação, com peso médio de $550 \mathrm{~kg}$ e produção de leite média de $20 \mathrm{~kg}$, distribuídas em três quadrados latinos balanceados (4x4), de acordo com o período de lactação, observando-se médias ao início do experimento de 115, 105 e 
100 dias de lactação, para os quadrados latinos 1, 2 e 3 , respectivamente.

Os tratamentos foram constituídos de quatro níveis de proteína bruta $(\mathrm{PB})$ nos concentrados: 20; 23; 26 e $29 \%$ na matéria natural (MN), sendo o concentrado utilizado na proporção de $30 \%$ na base da MS total da dieta, correspondendo aos teores de PB de 11,$3 ; 12,3 ; 13,3$ e $14,4 \%$ na base da MS total da dieta, respectivamente. Como volumoso, foi utilizada a silagem de milho na proporção de $70 \%$, na base da matéria seca total. As proporções dos ingredientes dos concentrados foram relatadas por Pereira et al. (2004). A composição bromatológica dos concentrados e da silagem de milho encontra-se na Tabela 1 e a composição das rações totais, na Tabela 2.

O experimento foi constituído de quatro períodos experimentais, com duração de 15 dias cada, sendo os primeiros sete dias de adaptação, conforme recomendado por Oliveira et al. (2001).

Os animais foram alojados em baias individuais providas de cocho e bebedouro automático. $\mathrm{O}$ alimento foi oferecido na forma de ração completa, misturada no cocho imediatamente antes do fornecimento aos animais, ad libitum, duas vezes ao dia, após as ordenhas da manhã e da tarde, de modo a permitir 5 a $10 \%$ de sobras. O peso de cada animal foi obtido pela média dos pesos ao início e final de cada período experimental e os consumos diários foram determinados pela diferença entre a dieta total oferecida e as sobras, que foram coletadas e pesadas duas vezes ao dia.

Semanalmente, foram coletadas amostras da silagem de milho para determinação de MS para o ajuste da relação V:C da dieta total. Para as amostras do alimento oferecido (silagem e concentrado) e das sobras, as coletas foram realizadas do 80 ao $15^{\circ}$ dias e, para as fezes, foram feitas diretamente da ampola retal, duas vezes em cada período experimental, uma às $8 \mathrm{~h}$ do $8 \underline{\mathrm{o}}$ dia e a outra às $15 \mathrm{~h}$ do $14 \underline{\mathrm{o}}$ dia, de acordo com Vagnoni et al. (1997). As amostras foram acondicionadas em sacos plásticos e armazenadas a $-20^{\circ} \mathrm{C}$ e, ao término do período de coletas, foram descongeladas, pré-secas em estufa de ventilação forçada a $60 \pm 5^{\circ} \mathrm{C}$, durante 72 a 96 horas, e processadas em moinho de facas com peneira contendo malhas de $1 \mathrm{~mm}$

Tabela 1 - Teores médios de matéria seca (MS), matéria orgânica (MO), proteína bruta (PB), proteína degradável no rúmen (PDR), proteína não-degradável no rúmen (PNDR), extrato etéreo (EE), carboidratos totais (CHOT), fibra em detergente neutro (FDN), fibra em detergente neutro corrigida para cinzas e proteína (FDNcp) e carboidratos não-fibrosos (CNF), proteína insolúvel em detergente ácido (PIDA) e lignina dos concentrados e da silagem de milho

Table 1 - Average contents of dry matter (DM), organic matter $(O M)$, crude protein $(C P)$, rumen degradable protein (RDP), rumen undegradable protein (RUP), ether extract (EE), total carbohydrates (TCHO), neutral detergent fiber (NDF), neutral detergent fiber corrected for ash and protein (NDFap), nonfiber carbohydrates (NFC), insoluble protein in acid detergent (IPAD) and lignin of the concentrates and corn silage

\begin{tabular}{|c|c|c|c|c|c|}
\hline \multirow[b]{2}{*}{ Item } & \multicolumn{4}{|c|}{$\begin{array}{c}\% \text { de PB na MN } \\
\% C P \text { in } N M\end{array}$} & \multirow[b]{2}{*}{$\begin{array}{l}\text { Silagem } \\
\text { Silage }\end{array}$} \\
\hline & 20 & 23 & 26 & 29 & \\
\hline $\operatorname{MS}(\%)(D M)(\%)$ & 86,03 & 86,13 & 86,05 & 85,86 & 29,60 \\
\hline $\mathrm{MO}^{1}(O M)$ & 93,97 & 93,36 & 92,90 & 92,47 & 93,73 \\
\hline $\mathrm{PB}^{1}\left(C P^{1}\right)$ & 23,39 & 26,06 & 29,83 & 33,25 & 6,40 \\
\hline $\mathrm{PDR}^{1}(R D P)$ & 15,67 & 17,85 & 20,76 & 23,39 & 4,90 \\
\hline $\mathrm{PNDR}^{1}(R U P)$ & $\begin{array}{r}1,01 \\
7,72\end{array}$ & $\begin{array}{r}11,07 \\
8,21\end{array}$ & $\begin{array}{r}20,0 \\
9,07\end{array}$ & 9,86 & 1,50 \\
\hline $\mathrm{EE}^{1}\left(E E^{I}\right) 4,27$ & 4,27 & 3,93 & 3,51 & 3,45 & 2,70 \\
\hline $\mathrm{CHOT}^{1}(\mathrm{TCHO})$ & 66,31 & 63,37 & 59,56 & 55,77 & 84,63 \\
\hline $\mathrm{FDN}^{1}(N D F)$ & 10,75 & 10,65 & 9,86 & 9,01 & 55,80 \\
\hline $\mathrm{FDNcp}^{1}$ (NDFap) & 8,93 & 8,72 & 8,26 & 7,70 & 54,05 \\
\hline $\mathrm{CNF}^{1}\left(N F C^{l}\right)$ & 55,56 & 52,72 & 49,70 & 46,76 & 28,83 \\
\hline PIDA (\% PB) & 7,14 & 5,37 & 6,94 & 5,29 & 15,0 \\
\hline$I P A D(\% C P)$ & & & & & \\
\hline Lignina $^{1}$ (Lignin) $^{\prime}$ & 2,73 & 2,44 & 2,73 & 3,10 & 4,36 \\
\hline
\end{tabular}

${ }^{1}$ Valores em percentagem da MS.

${ }^{1}$ Expressed in DM percentage. 
Tabela 2 - Teores médios de matéria seca (MS), matéria orgânica (MO), proteína bruta (PB), proteína degradável no rúmen (PDR), proteína nãodegradável no rúmen (PNDR), extrato etéreo (EE), carboidratos totais (CHOT), fibra em detergente neutro (FDN), fibra em detergente neutro corrigida para cinzas e proteína (FDNcp), carboidratos não-fibrosos (CNF), proteína insolúvel em detergente ácido (PIDA), lignina e nutrientes digestíveis totais (NDT), obtidos para as quatro dietas experimentais

Table 2 - Average contents of dry matter (DM), organic matter (OM), crude protein (CP), rumen degradable protein $(R D P)$, rumen undegradable protein (RUP), ether extract (EE), total carbohydrates (TCHO), neutral detergent fiber (NDF), neutral detergent fiber corrected for ash and protein (NDFpa), nonfiber carbohydrates (NFC), insoluble protein in acid detergent (IPAD), lignin and total digestible nutrients (TDN) obtained for the four experimental diets

\begin{tabular}{|c|c|c|c|c|}
\hline \multirow[t]{2}{*}{ Item } & \multicolumn{4}{|c|}{$\begin{array}{l}\text { Dieta experimental (\% PB na MS total) } \\
\text { Experimental diet (\% CP in dry matter basis) }\end{array}$} \\
\hline & 11,3 & 12,3 & 13,3 & 14,4 \\
\hline MS (\%) & 46,53 & 46,55 & 46,85 & 46,47 \\
\hline $\begin{array}{l}D M(\%) \\
\mathrm{MO}^{1} \\
O M^{1}\end{array}$ & 93,80 & 93,62 & 93,48 & 93,35 \\
\hline $\begin{array}{l}\mathrm{PB}^{1} \\
C P^{1}\end{array}$ & 11,3 & 12,3 & 13,3 & 14,4 \\
\hline $\begin{array}{l}\mathrm{PDR}^{1} \\
R D P^{l}\end{array}$ & 8,13 & 8,79 & 9,65 & 10,40 \\
\hline $\begin{array}{l}\mathrm{PNDR}^{1} \\
R U P^{1}\end{array}$ & 3,17 & 3,51 & 3,65 & 4,00 \\
\hline $\begin{array}{l}\mathrm{EE}^{1} \\
E E^{1}\end{array}$ & 3,17 & 3,06 & 2,94 & 2,92 \\
\hline $\begin{array}{l}\mathrm{CHOT}^{1} \\
\text { TCHO }^{1}\end{array}$ & 79,33 & 78,26 & 77,24 & 76,03 \\
\hline $\begin{array}{l}\mathrm{FDN}^{1} \\
N D F^{l}\end{array}$ & 44,62 & 43,55 & 43,31 & 44,82 \\
\hline $\begin{array}{l}\text { FDNcp }^{1} \\
\text { NDFap }\end{array}$ & 38,07 & 38,12 & 38,73 & 38,57 \\
\hline $\begin{array}{l}\mathrm{CNF}^{1} \\
N F C^{1}\end{array}$ & 34,71 & 34,71 & 33,93 & 31,21 \\
\hline $\begin{array}{l}\text { PIDA }(\% \text { da PB }) \\
I P A D(\% C P)\end{array}$ & 1,17 & 1,09 & 1,29 & 1,20 \\
\hline $\begin{array}{l}\text { Lignina }^{1} \\
\text { Lignin }^{1}\end{array}$ & 4,13 & 4,19 & 4,27 & 4,41 \\
\hline $\begin{array}{l}\mathrm{NDT}^{1} \\
T_{D N}^{1}\end{array}$ & 68,36 & 69,42 & 67,47 & 69,19 \\
\hline
\end{tabular}

${ }^{1}$ Valores em percentagem da MS (Expressed as DM percentage).

de diâmetro. Logo após, foram feitas amostras compostas com base no peso seco por animal em cada período experimental, que foram armazenadas para as análises bromatológicas.

As análises de MS, cinzas, EE, compostos nitrogenados totais (N) e FDN, nos alimentos, nas sobras e nas fezes foram realizadas conforme procedimentos descritos por Silva \& Queiroz (2002). A percentagem de carboidratos totais (CHOT) foi obtida por: $100-(\% \mathrm{~PB}+\% \mathrm{EE}+\%$ cinzas $)$, os carboidratos não-fibrosos (CNF) foram calculados como CHOT FDN (Snnifen et al. 1992) e, para o cálculo de nutrientes digestíveis totais (NDT), utilizou-se se a equação proposta pelo NRC (2001): NDT $=$ PBD + EEDx2,25 + FDND + CNFD, em que PBD, EED e CNFD representam os nutrientes digestíveis.

Para a determinação dos coeficientes de digestibilidade aparente total dos nutrientes, foi utilizada a fibra em detergente ácido indigestível (FDAi) como indicador interno, obtida após $144 \mathrm{~h}$ de incubação ruminal dos alimentos, das sobras e fezes, utilizando sacos da Ankon (Filter bags F57) (Cochran et al., 1986). Após o período de incubação, os sacos foram retirados dos animais e imediatamente lavados em água corrente até a mesma se apresentar totalmente límpida. Todos os sacos foram submetidos a fervura em detergente ácido durante uma hora.

Amostras de 5 gramas de silagem pré-seca em estufa a $60^{\circ} \mathrm{C}$, do fubá de milho e do farelo de soja, processadas em moinho de facas com peneira contendo malhas de $2 \mathrm{~mm}$ de diâmetro, foram colocadas em sacos de náilon de 10 × $20 \mathrm{~cm}$ e com $56 \mu \mathrm{m}$ de porosidade, para determinação das degradabilidades ruminais da PB e MS. Foram utilizadas três vacas fistuladas, alimentadas com a mesma dieta fornecida no último período experimental, adotando-se nove tempos de incubação $(0,2,4,8,16,24,48,72$ e 96 h), com três sacos para cada tempo. Antes e após a incubação, os sacos foram pesados para determinação de MS e para análise do $\mathrm{N}$ total. As equações, para estimar os parâmetros da degradabilidade, foram ajustadas ao modelo não-linear usando o método iterativo de Gauss-Newton, por intermédio do Sistema de Análises Estatísticas e Genéticas - SAEG (UFV, 1999).

Os coeficientes a, b e Kd, para determinação da degradabilidade da MS e PB foram obtidos da seguinte equação: Degradação da MS ou PB $=a+b\left(1-e^{-}\right.$ Kdt), em que $a=$ fração solúvel; $b=$ fração insolúvel potencialmente degradável; e $\mathrm{Kd}=$ taxa de degradação da fração b no tempo t. A degradabilidade efetiva da PB foi calculada pela equação PDR $=\mathrm{a}+(\mathrm{b} \times \mathrm{Kd}) /$ $(\mathrm{Kd}+\mathrm{Kp})$ onde $\mathrm{Kp}=$ taxa de passagem (Orskov \& McDonald, 1979). O conteúdo de PNDR foi calculado como 100 - PDR. 
A taxa de passagem foi calculada de acordo com o NRC (2001), utilizando as seguintes equações: Kp silagem $=3,054+0,614 \times$ CMS e Kp concentrado $=$ $2,904+1,375 \times$ CMS - 0,020 x \% de concentrado na dieta, em que CMS é o consumo de MS expresso em $\%$ do peso corporal (PC).

A produção de leite foi avaliada do $8 \underline{\mathrm{o}}$ ao $15^{\mathrm{o}}$ dia de cada período experimental. Amostras de leite da $1 \underline{\mathrm{a}}$ e $2^{\underline{a}}$ ordenhas do $10^{\underline{o}}$ dia foram coletadas e compostas por animal para determinação do teor de proteína, conforme descrito por Silva \& Queiroz (2002) e de gordura (Pregnolato \& Pregnolato, 1985). As amostras compostas foram obtidas pela mistura proporcional da ordenha da manhã e da tarde, conforme sugerido por Broderick \& Clayton (1997).

A produção de leite foi corrigida para $3,5 \%$ de gordura (PLG), pela equação citada por Sklan et al. (1992): $P L G=(0,432+0,1625 \times \mathrm{G}) \times \mathrm{kg}$ de leite, em que $\mathrm{G}=\%$ de gordura do leite.

A eficiência alimentar foi calculada para cada vaca, dividindo-se a produção média de leite pela ingestão média de MS de cada período experimental (Valadares Filho et al., 2000). Da mesma forma, procedeu-se ao cálculo da eficiência de $\mathrm{N}$, dividindo-se o N-total médio do leite pela ingestão média de N-total da dieta (Broderick, 2003).

Os resultados foram avaliados por meio de análises de variância e regressão, utilizando-se o Sistema de Análises Estatísticas e Genéticas - SAEG (UFV, 1999). Os critérios adotados para escolha do modelo foram o coeficiente de determinação $\left(R^{2}\right)$, que foi calculado como a relação entre a soma de quadrado da regressão e a soma de quadrado de tratamento e a significância observada por meio do teste $\mathrm{F}$, a $5 \%$ de probabilidade. Os três quadrados latinos foram analisados em conjunto.

\section{Resultados e Discussão}

Na Tabela 3, são apresentadas as estimativas dos parâmetros da degradabilidade in situ da MS e da PB. As degradabilidades efetivas médias calculadas para a MS e a PB dos alimentos foram, respectivamente, 51,87 e $76,63 \%$ para a silagem de milho; 59,46 e $47,32 \%$ para o fubá de milho e 74,51 e $72,55 \%$ para o farelo de soja, utilizando a taxa de passagem estimada de $0,064 . \mathrm{h}^{-1}$ para o concentrado e de $0,049 . \mathrm{h}^{-1}$ para a silagem de milho. Valadares Filho et al. (2002) citou
Tabela 3 - Frações solúveis (a) e insolúveis mas potencialmente degradáveis (b), taxa de degradação da fração b $(\mathrm{Kd})$ e degradabilidade efetiva (DE) estimadas para matéria seca (MS) e a proteína bruta (PB) dos alimentos utilizados nas rações de vacas no terço médio da lactação

Table 3 - Soluble fractions (a) and insoluble fractions potentially degradable (b), degradation rate of the fraction $b(K d)$ and effective degradability (ED) estimated for dry matter (DM) and crude protein $(C P)$ of the feeds used in rations for early lactation cows

\begin{tabular}{|c|c|c|c|c|}
\hline \multirow[t]{2}{*}{$\begin{array}{l}\text { Alimento } \\
\text { Feed }\end{array}$} & \multicolumn{3}{|c|}{$\begin{array}{l}\text { Parâmetro } \\
\text { Parameter }\end{array}$} & \multirow[t]{2}{*}{$\begin{array}{l}\mathrm{DE} \\
E D\end{array}$} \\
\hline & $\mathrm{a}$ & $\mathrm{b}$ & $\mathrm{Kd}$ & \\
\hline \multicolumn{5}{|c|}{ MS } \\
\hline $\begin{array}{l}\text { Silagem de milho } \\
\text { Corn silage }\end{array}$ & 26,26 & 56,08 & 0,041 & 51,87 \\
\hline $\begin{array}{l}\text { Fubá de milho } \\
\text { Corn meal }\end{array}$ & 26,47 & 73,00 & 0,053 & 59,46 \\
\hline $\begin{array}{l}\text { Farelo de soja } \\
\text { Soybean meal }\end{array}$ & 35,46 & 64,42 & 0,099 & 74,51 \\
\hline \multicolumn{5}{|c|}{ PB } \\
\hline $\begin{array}{l}\text { Silagem de milho } \\
\text { Corn silage }\end{array}$ & 48,00 & 51,99 & 0,060 & 76,63 \\
\hline $\begin{array}{l}\text { Fubá de milho } \\
\text { Corn meal }\end{array}$ & 24,99 & 66,99 & 0,032 & 47,32 \\
\hline $\begin{array}{l}\text { Farelo de soja } \\
\text { Soybean meal }\end{array}$ & 33,25 & 67,00 & 0,091 & 72,55 \\
\hline
\end{tabular}

valores da taxa de degradação da fração b da MS e da $\mathrm{PB}$, para os alimentos citados acima, próximos aos obtidos neste trabalho.

As médias referentes aos consumos diários de MS, MO, PB, EE, CHOT, FDN CNF e NDT, expressas em kg/dia, e de MS e FDN, expressas em porcentagem do peso vivo, são apresentadas na Tabela 4.

Não houve efeito dos níveis de proteína no concentrado sobre os consumos desses nutrientes, exceto para $\mathrm{PB}$, cujos teores se elevaram com o aumento de PB no concentrado. Conseqüentemente, os consumos de PDR e PNDR também aumentaram em função dos níveis de PB no concentrado. Para MS e FDN, os consumos expressos em $\mathrm{kg} /$ dia e em \%PV também não foram influenciados $(\mathrm{P}>0,05)$ pelos níveis de $\mathrm{PB}$ nos concentrados.

Resultados semelhantes foram observados por Kalscheur et al. (1999), que verificaram que vacas no terço médio da lactação, produzindo em média $25,42 \mathrm{~kg}$ de leite, consumiram em média 3,26 e 2,80 kg/dia de $\mathrm{PB}$, correspondendo, respectivamente, aos teores de 
Tabela 4 - Consumos médios diários de matéria seca (MS), matéria orgânica (MO), proteína bruta (PB), proteína degradável no rúmen (PDR), proteína não-degradável no rúmen (PNDR), extrato etéreo (EE), carboidratos totais (CHOT), fibra em detergente neutro (FDN), carboidratos não-fibrosos (CNF) e nutrientes digestíveis totais (NDT), em função dos níveis de proteína bruta no concentrado ( $\mathrm{X}$ em \%), coeficientes de variação (CV) e probabilidades $(P)$ referentes aos efeitos linear $(L)$ e quadrático $(Q)$ e equação de regressão

Table 4 - Daily average intakes of dry matter (DM), organic matter (OM), crude protein (CP), rumen degradable protein (RDP), rumen undegradable protein (RUP), ether extract (EE), total carbohydrates (TCHO), neutral detergent fiber (NDF), nonfiber carbohydrates (NFC) and total digestible nutrients (TDN), in function of the crude protein levels in the concentrate (X in \%), coefficients of variation $(C V)$ and probabilities $(P)$ related to the linear $(L)$ and quadract $(Q)$ effects and regression equation

\begin{tabular}{|c|c|c|c|c|c|c|c|}
\hline \multirow[t]{2}{*}{ Item } & \multicolumn{4}{|c|}{$\begin{array}{l}\text { Nível de proteína (\% na MN) } \\
\text { Protein level (\% in natural matter) }\end{array}$} & \multirow[t]{2}{*}{ CV\% } & \multicolumn{2}{|c|}{$\mathrm{P}$} \\
\hline & 20 & 23 & 26 & 29 & & $\mathrm{~L}$ & Q \\
\hline & \multicolumn{7}{|c|}{ Consumo (kg/dia) } \\
\hline $\begin{array}{l}\text { MS } \\
D M\end{array}$ & 16,07 & 16,37 & 16,73 & 17,01 & 3,64 & n.s. & n.s. \\
\hline $\begin{array}{l}\mathrm{MO} \\
\text { OM }\end{array}$ & 15,08 & 15,33 & 15,66 & 15,88 & 3,60 & n.s. & n.s. \\
\hline $\begin{array}{l}\mathrm{PB} \\
C P\end{array}$ & 1,93 & 2,08 & 2,36 & 2,56 & 3,21 & 0,00001 & n.s. \\
\hline $\begin{array}{l}\mathrm{PDR}(\mathrm{g} / \mathrm{dia}) \\
R D P(\text { g/day })\end{array}$ & 1,33 & 1,45 & 1,66 & 1,81 & & & \\
\hline $\begin{array}{l}\operatorname{PNDR}(\mathrm{g} / \text { dia }) \\
R U P(\text { g/day })\end{array}$ & 0,54 & 0,58 & 0,65 & 0,69 & & & \\
\hline $\begin{array}{l}\mathrm{EE} \\
E E\end{array}$ & 0,53 & 0,53 & 0,52 & 0,52 & 4,50 & n.s. & n.s. \\
\hline $\begin{array}{l}\text { CHOT } \\
\text { TCHO }\end{array}$ & 12,62 & 12,74 & 12,79 & 12,82 & 3,70 & n.s. & n.s. \\
\hline $\begin{array}{l}\text { FDN } \\
N D F\end{array}$ & 6,57 & 6,74 & 6,83 & 6,70 & 4,09 & n.s. & n.s. \\
\hline $\begin{array}{l}\mathrm{CNF} \\
\mathrm{NFC}\end{array}$ & 6,05 & 5,99 & 5,96 & 5,82 & 4,13 & n.s. & n.s. \\
\hline $\begin{array}{l}\text { NDT } \\
T D N\end{array}$ & 10,97 & 11,40 & 11,26 & 11,73 & 7,53 & n.s. & n.s. \\
\hline & \multicolumn{7}{|c|}{$\begin{array}{l}\text { Consumo (\% do PC) } \\
\text { Intake (\% body weight) }\end{array}$} \\
\hline $\begin{array}{l}\mathrm{MS} \\
D M\end{array}$ & 2,93 & 2,96 & 3,03 & 3,06 & 3,17 & n.s. & n.s. \\
\hline $\begin{array}{l}\text { FDN } \\
N D F\end{array}$ & 1,19 & 1,22 & 1,23 & 1,26 & 4,43 & n.s. & n.s. \\
\hline
\end{tabular}

n.s.: não-significativo $(P>0,05)$ (not significant, $P>$.05).

${ }^{1} \hat{\mathrm{Y}}=0,4784+0,0716 \mathrm{X}\left(\mathrm{r}^{2}=0,99\right)$.

15,3 e de $13,3 \%$ PB, não havendo efeito significativo sobre a ingestão de MS.

$\mathrm{Wu} \&$ Satter (2000) relataram que a ingestão de MS tendeu a ser maior $(\mathrm{P}<0,1)$ para o grupo de vacas que estavam entre 17 e 44 semanas de lactação, produzindo entre 30,1 a $33,8 \mathrm{~kg}$ de leite por dia, alimentadas com dietas contendo 17,4-17,9\% de PB em relação aos grupos no mesmo estádio de lactação submetidos a 15,4-16,0 e 17,4-16,0\% de PB na dieta.

Resultados opostos foram obtidos por Jones-Endsley et al. (1999), com vacas no terço médio da lactação em pastejo rotacionado, produzindo diariamente 36 a $46 \mathrm{~kg}$ de leite. Verificaram aumentos significativos dos consumos totais e da digestão aparente total de MS, MO e
FDN, quando o nível de PB e a quantidade do suplemento foram elevados de 12 para $16 \%$ de PB e de 6,4 para $9,6 \mathrm{~kg} / \mathrm{dia}$, respectivamente.

Efeito linear positivo para o consumo de MS em relação aos níveis crescentes do nitrogênio dietético foi observado por Broderick (2003), em vacas com 130 dias de lactação, produzindo em média $34 \mathrm{~kg}$ de leite por dia, alimentadas com dietas contendo 15,1 ; 16,7 e $18,4 \%$ de PB, compostas de silagem de alfafa e de milho (na proporção de 3:2), independentemente dos teores de FDN nas dietas.

Segundo Mertens (1987), há limitação física no consumo em relação ao retículo-rúmen (limitação física), principalmente pela FDN da dieta, e fisiológica, 
quando a dieta se encontra além das necessidades energéticas do animal. A falta de resposta do consumo de MS frente ao aumento de PB da dieta pode estar relacionada à densidade energética e à fração de FDN da dieta. Independentemente do teor de PB, todos os tratamentos atenderam aos requerimentos de energia metabolizável. Além disso, ao se observar a exigência nutricional dos animais, verifica-se que todas as dietas com nível acima de $12,3 \%$ de PB podem estar além das exigências para proteína metabolizável dos animais, considerando que as vacas já se encontram no terço médio da lactação, produzindo em média $20 \mathrm{~kg}$ de leite por dia.

O NRC (2001) prediz consumo de MS de 16,9 kg/ dia para vacas de $550 \mathrm{~kg}$ de peso vivo produzindo 20 $\mathrm{kg}$ de leite por dia na 20a semana de lactação, ganhando $0,2 \mathrm{~kg} / \mathrm{dia}$. Esse valor é muito próximo dos observados nesse experimento, que variaram de 16,1 a $17,0 \mathrm{~kg} / \mathrm{dia}$.

Os coeficientes de digestibilidade aparente total da MS, MO, PB, EE, CHOT, FDN e CNF com seus respectivos coeficientes de variação, encontram-se na Tabela 5, não sendo observado efeito dos níveis de PB sobre essas digestibilidades, exceto para PB.
Os coeficientes médios de digestibilidade de MS, MO, FDN, EE, PB, CHOT e CNF foram de 68,96; 70,$17 ; 56,49 ; 79,20 ; 71,95 ; 69,46$ e $85,79 \%$, respectivamente. Valores bem próximos foram encontrados por Oliveira et al. (2001), para os coeficientes da MS, MO, PB e CHOT.

A digestibilidade da FDN não variou $(\mathrm{P}>0,05)$ com o aumento dos níveis de PB. Comparando com os dados observados por Pereira et al. (2005), em que se utilizou a relação V:C (60:40), os consumos de MS obtidos foram mais elevados, no entanto, os valores médios de digestibilidade entre os dois experimentos foram semelhantes, exceto para a ração com 16,9\% de $\mathrm{PB}$, que apresentou melhoria percentual de $10,42 \%$.

Apesar de a relação $\mathrm{V}: \mathrm{C}$ interferir na digestão da fibra, como foi observada a sua redução por Reis (2000), ao mudar a relação V:C de 60:40 para 40:60 e por Galyean \& Goetsch (1993), que observaram decréscimo a partir da proporção 70:30, nos dois experimentos, a fração de FDN das dietas que foi digerida parece não ter sido afetada pela mudança da relação $\mathrm{V}: \mathrm{C}$ de 60:40 para 70:30. Considerando o fato de a digestibilidade da FDN ter sido positivamente afetada pelos níveis de PB da ração no primeiro experimento,

Tabela 5 - Valores médios de coeficientes de digestibidade aparente total da matéria seca (DMS), matéria orgânica (DMO), proteína bruta (DPB), extrato etéreo (DEE), carboidratos totais (DCHOT), fibra em detergente neutro (DFDN) e carboidratos não-fibrosos (DCNF), em função dos níveis de proteína bruta no concentrado (X em $\%)$, coeficientes de variação $(\mathrm{CV})$, probabilidades $(P)$ referentes aos efeitos linear $(L)$ e quadrático $(Q)$ e equação de regressão

Table 5 - Average values of coefficients of total apparent digestibility of dry matter (DMD), organic matter (OMD), crude protein $(C P D)$, ether extract (EED), total carbohydrates (TCHOD), neutral detergent fiber (NDFD) and nonfiber carbohydrates (NFCD) in function of the crude protein levels in the concentrate ( $X$ in \%), coefficients of variation (CV) and probabilities $(P)$ related to the linear $(L)$ and quadract $(Q)$ effects and regression equation

\begin{tabular}{|c|c|c|c|c|c|c|c|}
\hline \multirow[t]{2}{*}{ Item } & \multicolumn{4}{|c|}{$\begin{array}{l}\text { Nível de proteína (\% na MN) } \\
\text { Protein level (\% in natural matter) }\end{array}$} & \multirow[t]{2}{*}{ CV\% } & \multicolumn{2}{|c|}{$\mathrm{P}$} \\
\hline & 20 & 23 & 26 & 29 & & $\mathrm{~L}$ & Q \\
\hline $\begin{array}{l}\text { DMS } \\
D M D\end{array}$ & 68,56 & 69,60 & 68,05 & 69,64 & 6,28 & n.s. & n.s. \\
\hline $\begin{array}{l}\mathrm{DMO} \\
O M D\end{array}$ & 69,70 & 70,76 & 69,21 & 71,04 & 5,84 & n.s. & n.s. \\
\hline $\begin{array}{l}\mathrm{DPB} \\
C P D\end{array}$ & 67,87 & 72,09 & 71,15 & 76,70 & 8,25 & $0,0012^{1}$ & n.s. \\
\hline $\begin{array}{l}\mathrm{DEE} \\
E E D\end{array}$ & 78,44 & 79,62 & 77,86 & 80,88 & 5,04 & n.s. & n.s. \\
\hline $\begin{array}{l}\text { DCHOT } \\
\text { TCHOD }\end{array}$ & 69,61 & 70,17 & 68,52 & 69,53 & 6,40 & n.s. & n.s. \\
\hline $\begin{array}{l}\text { DFDN } \\
N D F D\end{array}$ & 55,79 & 57,40 & 55,21 & 57,57 & 11,96 & n.s. & n.s. \\
\hline $\begin{array}{l}\text { DCNF } \\
N F C D\end{array}$ & 86,22 & 86,00 & 85,44 & 85,49 & 3,96 & n.s. & n.s. \\
\hline
\end{tabular}

n.s.: não-significativo $(P>0,05)$ (not significant, $P>05)$.

${ }^{1} \hat{\mathrm{Y}}=51,0944+0,8514 \mathrm{X}\left(\mathrm{r}^{2}=0,82\right)$. 
ocorre a possibilidade de o aumento do conteúdo de PB da ração ter anulado o efeito negativo da diminuição da relação V:C da dieta e do aumento do consumo de MS sobre a digestibilidade da fibra.

Os valores médios de produção de leite e as porcentagens de gordura e proteína do leite não variaram $(\mathrm{P}>0,05)$ nos diferentes níveis de $\mathrm{PB}$ do concentrado (Tabela 6). Contudo, a produção de leite corrigida para $3,5 \%$ de gordura e as quantidades de gordura e proteína aumentaram linearmente.

Os resultados de produção de leite mostram que entre os níveis 20 e $23 \%$ de $\mathrm{PB}$ na $\mathrm{MN}$ do concentrado, houve melhoria de $6,98 \%$ ou $1,34 \mathrm{~kg}$ de leite por dia.

Kalscheur et al. (1999) reportaram que, no terço médio da lactação, as vacas alimentadas com dieta contendo $15,3 \%$ de PB não apresentaram melhores respostas para a produção de leite em relação às vacas submetidas às dietas contendo $13,3 \%$ de $P B$, indicando que dietas para vacas nesse estádio de lactação podem ser formuladas com menor concentração de PB. Não observaram efeito causado pela variação na PNDR $(4,79 ; 5,52$ e 6,38\% na base da MS da dieta) para os tratamentos com 13,3\% de PB.
Resultados semelhantes foram obtidos nesse experimento, mas a variação da PNDR compreendeu valores de 3,18; 3,43; 3,67 e 3,92\% para os níveis de 11,3; 12,$3 ; 13,3$ e $14,4 \%$ de $\mathrm{PB}$, respectivamente.

Robinson \& Kennelly (1988) e Robinson et al. (1991) comprovaram que vacas, nos terços médio e final de lactação, alimentadas com dietas apresentando redução de 15 a 60\% de PNDR em relação ao preconizado pelo NRC (1989), não apresentaram queda na produção de leite. Resultados semelhantes foram relatados por Dunlap et al. (1991) em um estudo que avaliou a redução de $200 \mathrm{~g} / \mathrm{dia}$ da PNDR em relação ao requerimento médio de um grupo de vacas no terço médio da lactação, quando alimentadas com rações contendo alto teor energético e PDR. Estes resultados indicaram que dietas formuladas com menores concentrações de PB dietética podem proporcionar produção de leite equivalente à de vacas alimentadas com maiores níveis de $\mathrm{PB}$. O efeito da PNDR sobre a produção de leite em vacas no terço inicial da lactação é diferente daquele obtido nos terços médio e final da lactação, o que pode ser evidenciado por vários estudos (Arieli

Tabela 6 - Valores médios de produção de leite não-corrigida (PL) e corrigida para 3,5\% de gordura (PLG), eficiência de utilização de MS (kg leite/kg matéria seca consumida), eficiência de utilização de N (kg N-leite/kg N-ingerido), teores e quantidades de gordura $(G)$ e proteína bruta $(P B)$ do leite, em função dos níveis de proteína bruta no concentrado, coeficientes de variação $(C V)$, probabilidades $(P)$ para os efeitos linear $(L)$ e quadrático $(Q)$ e equações de regressão

Table 6 - Average values of milk production (MP) and corrected for $3.5 \%$ fat (FMP), efficiency of dry matter assimilation (kg milk/ $\mathrm{kg}$ dry matter intaked), efficiency of nitrogen compounds $(\mathrm{N})$ assimilation ( $\mathrm{kg} \mathrm{N}$-milk/kg N-intaked), concentration and quantity of milk fat $(F)$ and crude protein $(C P)$, in function of the crude protein level in the concentrate $(X$ in \%), coefficients of variation $(C V)$ and probabilities $(P)$ related to the linear $(L)$ and quadract $(Q)$ effects and regression equations

\begin{tabular}{|c|c|c|c|c|c|c|c|}
\hline \multirow[t]{2}{*}{ Item } & \multicolumn{4}{|c|}{$\begin{array}{l}\text { Nível de proteína (\% na MN) } \\
\text { Protein level (\% in natural matter) }\end{array}$} & \multirow[t]{2}{*}{ CV\% } & \multicolumn{2}{|c|}{$\mathrm{P}$} \\
\hline & 20 & 23 & 26 & 29 & & $\mathrm{~L}$ & Q \\
\hline $\begin{array}{l}\mathrm{PL}(\mathrm{kg} / \mathrm{dia}) \\
M P(k g / d a y)\end{array}$ & 17,87 & 19,21 & 19,47 & 19,49 & 5,14 & n.s & n.s. \\
\hline $\begin{array}{l}\mathrm{PLG}(\mathrm{kg} / \mathrm{dia}) \\
F M P(\mathrm{~kg} / \text { day })\end{array}$ & 18,90 & 20,74 & 20,65 & 21,27 & 6,48 & $0,0478^{1}$ & n.s. \\
\hline $\begin{array}{l}\text { Eficiência MS } \\
\text { DM efficiency }\end{array}$ & 1,12 & 1,19 & 1,17 & 1,15 & 5,28 & n.s. & n.s. \\
\hline $\begin{array}{l}\text { Eficiência N } \\
N \text { efficiency }\end{array}$ & 0,312 & 0,308 & 0,274 & 0,267 & 5,22 & $0,0018^{2}$ & n.s. \\
\hline $\begin{array}{l}\mathrm{G}(\%) \\
F(\%)\end{array}$ & 3,94 & 4,07 & 3,97 & 4,14 & 5,99 & n.s. & n.s. \\
\hline $\begin{array}{l}\mathrm{G}(\mathrm{g} / \mathrm{dia}) \\
F(\text { g/day })\end{array}$ & 688,93 & 766,75 & 754,73 & 791,63 & 8,34 & $0,030^{3}$ & n.s. \\
\hline $\begin{array}{l}\mathrm{PB}(\%) \\
C P(\%)\end{array}$ & 3,44 & 3,42 & 3,40 & 3,58 & 3,91 & n.s. & n.s \\
\hline $\begin{array}{l}\mathrm{PB}(\mathrm{g} / \text { dia }) \\
C P(\text { g/day })\end{array}$ & 607,81 & 648,96 & 654,38 & 688,91 & 4,92 & $0,0183^{4}$ & n.s. \\
\hline
\end{tabular}

n.s.: não-significativo $(P>0,05)$ (not significant, $P>.05)$.

${ }^{1} \hat{Y}=14,6654+0,2337 X\left(r^{2}=0,77\right) ;{ }^{2} \hat{Y}=0,4284-0,0056 X\left(r^{2}=0,89\right) ;{ }^{3} \hat{Y}=508,698+9,8699 X\left(r^{2}=0,76\right) ;{ }^{4} \hat{Y}=446,880+8,2913 X\left(r^{2}=0,93\right)$ 
et al., 1996; Armentano et al., 1993; Robinson et al., 1991; Robinson \& Kennelly, 1988).

Para a produção de leite corrigida para $3,5 \%$ de gordura, os aumentos foram de $9,74 \%$, ou $1,84 \mathrm{~kg} / \mathrm{dia}$, e as produções de gordura e proteína apresentaram incrementos de $0,08 \mathrm{~kg} /$ dia e $0,04 \mathrm{~kg} /$ dia, respectivamente, entre os níveis 20 e $23 \%$ de $\mathrm{PB}$ na $\mathrm{MN}$ do concentrado. Esses acréscimos foram numericamente superiores quando comparados com os níveis 12,313,3 e $12,3-14,3 \%$ de PB, apesar de o efeito linear positivo ter sido estatisticamente significativo.

Comportamento linear positivo também foi encontrado por Broderick (2003) para as produções de leite não-corrigida e corrigida para 3,5\% de gordura, bem como para as produções de gordura e proteína do leite, quando utilizou dietas contendo 15,1; 16,7 e 18,4\% de PB. Contudo, Kalscheur et al. (1999) e Jones-Endsley et al. (1997) não encontraram diferenças significativas para a produção e composição química do leite, ao compararem dietas contendo 13,3 ou $15,3 \%$ de PB e 12,3 ou $16,1 \%$ de $\mathrm{PB}$, respectivamente.

A FDN da silagem de milho supriu, em média, $88,61 \%$ de toda a FDN em todas as rações e os teores de FDN oscilaram de 39,39 a 40,88\% da MS da dieta consumida, o que provavelmente não influenciou o teor de gordura do leite.

Os valores observados para o conteúdo de proteína do leite (Tabela 6) estão acima do limite mínimo de $30 \mathrm{~g} / \mathrm{L}$, o que, segundo Wittwer (2000), é considerado normal.

As eficiências alimentar e de conversão de compostos nitrogenados $(\mathrm{N})$ estão apresentadas na Tabela 6 . As semelhanças numéricas entre as médias de eficiência alimentar obtidas entre os níveis 12,3; 13,3 e 14,4\% de $\mathrm{PB}$ indicam que os níveis de $\mathrm{PB}$ acima de $12,3 \%$ na MS total podem ter fornecido excesso de PDR, tendo em vista que os consumos de MS e CNF não se elevaram. $\mathrm{O}$ tratamento de menor conteúdo protéico resultou na mais alta eficiência para conversão do $\mathrm{N}$ dietético em $\mathrm{N}$ do leite, mas, de acordo com as recomendações do NRC (1989), este tratamento foi claramente deficiente em PB. Vários autores têm evidenciado valores mais elevados nessa eficiência, quando os níveis de PB na dieta são menores (Kalscheur et al.,1999; Wu \& Satter, 2000; Broderick, 2003). Wu \& Satter (2000) relataram que é difícil converter $\mathrm{N}$ alimentar em $\mathrm{N}$ do leite que ultrapasse $30 \%$ quando se fornece ração com menor conteúdo de proteína e que ainda consiga manter a produção de leite, principalmente quando se utiliza proteína de soja como fonte suplementar. Contudo, nas condições deste experimento, a dieta contendo nível de $12,3 \%$ de PB proporcionou $30,8 \%$ de eficiência para utilização do nitrogênio.

$\mathrm{Na}$ Tabela 7, constam as exigências preditas pelo NRC (2001) e as obtidas para as vacas utilizadas neste estudo. O consumo de MS predito pelo NRC (2001) para vacas produzindo $20 \mathrm{~kg}$ de leite é de 16,9 $\mathrm{kg} /$ dia, valor próximo aos 16,4 kg MS/dia observado para vacas produzindo $19,0 \mathrm{~kg}$ de leite, ou seja, alimentadas com concentrado contendo $23 \%$ de PB na matéria natural.

De maneira semelhante, o consumo de NDT predito pelo NRC (2001), de 9,8 kg/dia, foi próximo ao valor observado $(11,4 \mathrm{~kg}$ de NDT/dia) para vacas produzindo $19,0 \mathrm{~kg}$ de leite por dia.

Os valores preditos pelo NRC (2001) como exigên-

Tabela 7 - Consumo médio diário de matéria seca (CMS), proteína bruta (CPB), proteína degradável no rúmen (CPDR), proteína não-degradável no rúmen (CPNDR) e exigências nutricionais de proteína e energia preditas pelo NRC (2001) e obtidas neste experimento para vacas com $550 \mathrm{~kg}$, produzindo diariamente $20 \mathrm{~kg}$ de leite com $3,5 \%$ de gordura, ganhando $0,2 \mathrm{~kg}$ de peso corporal, na 20a semana de lactação

Table 7 - Daily average intake of dry matter (DMI), crude protein (CPI), rumen degradable protein (RDPI), rumen undegradable protein (RUPI) and energy and protein requirements predicted for the NRC (2001) and obtained in the present experiment for cows in twentieth week in milk,550 kg live weight, $0.2 \mathrm{~kg}$ body weight gain and $20 \mathrm{~kg}$ daily milk production with $3.5 \%$ fat

\begin{tabular}{|c|c|c|}
\hline Item & $\begin{array}{l}\text { Predito pelo NRC }(2001) \\
\quad N R C \text { (2001) predict }\end{array}$ & $\begin{array}{c}\text { Observado } \\
\text { Observed }\end{array}$ \\
\hline CMS (kg/dia) & 16,9 & 16,4 \\
\hline $\begin{array}{l}\text { DMI (kg/day) } \\
\text { CPB (g/dia) }\end{array}$ & 2513 & 2080 \\
\hline $\begin{array}{l}C P I \text { (g/day) } \\
\text { CPDR (g/dia) } \\
\text { RDPI (g/day) }\end{array}$ & 1469 & 1450 \\
\hline $\begin{array}{l}\text { CPNDR (g/dia) } \\
\text { RUPI (g/day) }\end{array}$ & 1044 & 580 \\
\hline $\begin{array}{l}\mathrm{CPM}(\mathrm{g} / \text { dia })^{1} \\
M P I(\text { g/day })^{1}\end{array}$ & 1527,5 & \\
\hline $\begin{array}{l}\mathrm{EL}_{\mathrm{L}}(\mathrm{Mcal} / \mathrm{dia})^{2} \\
N E_{L}\left({\text { Mcal } / \text { day })^{2}}^{2}\right.\end{array}$ & 22,9 & \\
\hline $\begin{array}{l}\mathrm{NDT}(\mathrm{kg} / \mathrm{dia})^{3} \\
T D N(\mathrm{~kg} / \text { day })^{3}\end{array}$ & $9,8^{4}$ & 11,4 \\
\hline
\end{tabular}

\footnotetext{
${ }^{1}$ Consumo de proteína metabolizável (metabolizable protein intake). 2 Energia líquida de lactação (net energy lactation).

${ }^{3}$ Consumo de nutrientes digestíveis totais (total digestible nutrients intake).

4 Estimado: $\mathrm{EL}_{\mathrm{L}} / 0,65 \times 0,82 \times 4,409$ (Estimated: $N E_{L} / .65 \times .82 \times 4.409$ ).
} 
cias de proteína para vacas produzindo $20 \mathrm{~kg}$ de leite/ dia são de 2.513, 1.469 e $1.044 \mathrm{~g} /$ dia, respectivamente, para PB, PDR e PNDR, enquanto os encontrados nesta pesquisa foram de $2.080,1.450$ e $580 \mathrm{~g} / \mathrm{dia}$, respectivamente, que são aproximadamente de $17 \%$ inferiores para PB. Assim, os valores de proteína que resultaram em maior produção de leite neste estudo foram de $12,3 \%$ de PB na MS total da dieta, ou $23 \%$ de PB na base da matéria natural do concentrado, dos quais aproximadamente $8,79 \%$ de PDR e $3,51 \%$ de PNDR. O NRC (2001) sugere também um valor de $8,7 \%$ de PDR (na base da MS) para vacas produzindo aproximadamente $20 \mathrm{~kg}$ de leite diariamente.

\section{Conclusões}

Vacas no terço médio da lactação produzindo em média $20 \mathrm{~kg}$ de leite por dia e alimentadas com $70 \%$ de silagem de milho na base da matéria seca devem consumir concentrado com $23 \%$ de PB na matéria natural, o que resulta em $12,3 \%$ de PB na dieta total.

\section{Literatura Citada}

ARIELI, A.; SHABI, Z.; BRUCKENTAL, I. et al. Effect of the degradation of organic matter and crude protein on ruminal fermentation in dairy cows. Journal of Dairy Science, v.79, n.10, p.1774-1780, 1996.

ARMENTANO, L.E.; BERTICS, S.J.; RIESTERER, J. Lack of response to addition of degradable protein to a low protein diet fed to midlactation dairy cows. Journal of Dairy Science, v.76, n.12, p.3755-3762, 1993.

BRODERICK, G.A. Effects of varying dietary protein and energy levels on the production of lactating dairy cows. Journal of Dairy Science, v.86, n.4, p.1370-1381. 2003.

BRODERICK, G.A.; CLAYTON, M.K. A statistical evaluation of animal and nutritional factors influencing concentrations of milk urea nitrogen. Journal of Dairy Science, v.80, n.11, p.2964-2971, 1997.

COCHRAN, R.C.; ADAMS, D.C.; WALLACE, J.D. et al. Predicting digestibility of different diets with internal markers: evaluation of four potential markers. Journal of Animal Science, v.63, p.1476-1483, 1986.

DINN, N.E.; SHELFORD, J.A.; FISHER, L.J. Use of the Cornell Net Carbohydrate and Protein System and rumenprotected lysine and methionine to reduce nitrogen excretion from lactating cows. Journal of Dairy Science, v.81, n.1, p.229-237, 1998.

DUNLAP, T.F.; KOHN, R.A.; DOUGLASS, L.W. et al. Diets deficient in rumen undegraded protein did not depress milk production. Journal of Dairy Science, v.83, n.8, p.1806-1812, 2000.

GALYEAN, M.L.; GOETSCH, A.L. Utilization of forage fiber by ruminants. In: JUNG, H.G.; BUXTON, R.D. (Eds). Forage cell wall structure and digestibility. Madison: ASA-CSSA-SSSA, 1993. p.34-62.
GUSTAFSSON, A.H.; HELANDER, M.; LINDGREN, E. et al. Methods for improving nitrogen efficiency in dairy production by dietary protein changes. http:// www.ammoniak.nu/utfodring/index_eng.htm. Acesso em: junho de 2003.

JONES-ENDSLEY, J.M.; CECAVA, M.J.; JOHNSON, T.R. Effects of dietary supplementation on nutrient digestion and the milk yield of intensively grazed lactating dairy cows. Journal of Dairy Science, v.80, n.12, p.3283-3292, 1997.

KALSCHEUR, K.F.; VANDERSALL, J.H.; ERDMAN, R.A. et al. Effects of dietary crude protein concentration and degradability on milk production responses of early, mid, and late lactation dairy cows. Journal of Dairy Science, v.82, n.3, p.545-554, 1999.

McCORMICK, M.E.; FRENCH, D.D.; BROWN, T.F. et al. Crude protein and rumen undegradable protein effects on reproduction and lactation performance of Holstein cows. Journal of Dairy Science, v.82, n.12, p.2697-2708, 1999.

MERTENS, D.R. Predicting intake and digestibility using mathematical models of animal function. Journal of Animal Science, v.64, p.1548-1558, 1987.

NATIONAL RESEARCH COUNCIL - NRC. Nutrient requirements of dairy cattle. 6.ed. Washington, D.C.: National Academic Press, 1989. 158p.

NATIONAL RESEARCH COUNCIL - NRC. Nutrient requirements of dairy cattle. 7.rev.ed. Washington, DC.: National Academic Press, 2001. 381p.

NEIVA, R.S. Produção de bovinos leiteiros. 1.ed. Lavras: Universidade Federal de Lavras, 1998. 534p.

OLIVEIRA, A.S.; VALADARES, R.F.D.; VALADARES FILHO, S.C. et al. Consumo, digestibilidade aparente, produção e composição do leite em vacas alimentadas com quatro níveis de compostos nitrogenados não protéicos. Revista Brasileira de Zootecnia, v.30, n.4, p.1358-1366, 2001.

ORSKOV, E.R.; McDONALD, I. The estimation of protein degradabilility in the rumen from incubation measurements weighted according to rate of passage. Journal of Agricultural Science, v.92, p.499-503, 1979.

PAUL, J.W.; DINN, N.E.; DANNANGARA, T.; FISHER, L.J. Protein content in dairy cattle diets affects ammonia losses and fertilizer nitrogen value. Journal of Environmental Quality, v.27, p.528-534, 1998.

PEREIRA, M.L.A.; VALADARES FILHO, S.C.; VALADARES, R.F.D. et al. Consumo, digestibilidade aparente total, produção e composição do leite em vacas no terço inicial da lactação alimentadas com níveis crescentes de proteína bruta no concentrado. Revista Brasileira de Zootecnia, v.34, n.3, p.1029-1039, 2005.

PREGNOLATO, W.; PREGNOLATO, N.P. Normas analíticas do instituto Adolfo Lutz. In: Métodos químicos e físicos para análise de alimentos. 3.ed. São Paulo: Instituto Adolfo Lutz. v.1, 1985. 533p.

REIS, C.S. Utilização do capim-elefante (Pennisetum purpureum Schum. CV. MINEIRO), submetido a adubação química e orgânica, na alimentação de vacas leiteiras. Viçosa, MG: Universidade Federal de Viçosa, 2000. 109p. Dissertação (Mestrado em Zootecnia) - Universidade Federal de Viçosa, 2000.

VALADARES FILHO, S.C.; ROCHA JR., V.R.; CAPPELLE, E.R. Tabelas brasileiras de composição de alimentos para bovinos. CQBAL 2.0. Viçosa, MG: Universidade Federal de Viçosa, 2002. 297p. 
ROBINSON, P.H.; KENNELLY, J.J. Influence of intake of rumen undegradable protein on milk production of late lactation Holstein cows. Journal of Dairy Science, v.71, n.8, p.2135-2142, 1988.

ROBINSON, P.H.; McQUEEN, R.E.; BURGESS, P.L. Influence of rumen undegradable protein levels on feed intake and milk production of late lactation of dairy cows. Journal of Dairy Science, v.74, n.5, p.1623-1631, 1991.

SILVA, D.J.; QUEIROZ, A.C. Análise de alimentos: métodos químicos e biológicos. 3.ed. Viçosa, MG: Universidade Federal de Viçosa, 2002. 235p.

SKLAN, D.; ASHKENNAZI, R.; BRAUN, A. et al. Fatty acids, calcium soaps of fatty acids, and cottonseeds fed to high yielding cows. Journal of Dairy Science, v.75, n.9, p.2463-2472, 1992.

SMITS, M.C.J.; VALK, H; ELZING, A. et al. Effect of protein nutrition on ammonia from a cubicle house for dairy cattle. Livestock Production Science, v.44, n.1, p.47-156, 1995.

SNIFFEN, C.J.; O'CONNOR, J.D.; VAN SOEST, P.S. A net carbohydrate and protein availability. Journal of Animal Science, v.70, n. 11, p.3562-3577, 1992.

UNIVERSIDADE FEDERAL DE VIÇOSA - UFV. Sistema de análises estatísticas e genéticas - SAEG. Viçosa, MG: UFV. 1999. (Apostila).
VAGNONI, D.B., BRODERICK, G.A., CLAYTON, M.K. et al. Excretion of purine derivatives by Holstein cows abomasally infused with incremental amounts of purines. Journal of Dairy Science, v.80, n.8, p.695-1702, 1997.

VALADARES FILHO, S.C.; BRODERICK, G.A.; VALADARES, R.F.D. et al. Effect of replacing alfafa silage with high moisture corn on nutrient utilization and milk production. Journal of Dairy Science, v.83, n.1, p.106-114, 2000.

WITTWER, F. Diagnóstico dos desequilíbrios metabólicos de energia. In: GONZALEZ, F.H.D.; BARCELLOS, J.O.; OSPINA, H.; RIBEIRO, L.A.O. (Eds.) Perfil metabólico em ruminantes: seu uso em nutrição e doenças nutricionais. Porto Alegre: Universidade Federal do Rio Grande do Sul, 2000. p.9-22.

WU, Z.; SATTER, L.D. Milk production during the complete lactation of dairy cows fed diets containing different amount of protein. Journal of Dairy Science, v.83, n.5, p.1042-1051, 2000.

Recebido em: 16/12/03

Aceito em: 16/02/05 